421

Perdas e ganhos, de Peter Burke

Mariana Holms

DOI 10.11606/ISSN.2447-8997.TERESA.2020.158961 


\section{Deslocamentos produtivos}

PETER BURKE.

Perdas e ganhos: exilados e expatriados na história do conhecimento na Europa e nas Américas, 1500-2000.

Editora Unesp, 2017. 


$$
0
$$


reflexão filológica é o ponto de partida do livro: como chamar as pessoas que deixaram o seu país de origem? Como elas preferiam se chamar nas suas memórias e cartas? Réfugié, Flüchtling, desterrado, displaced person? A forma como as pessoas exiladas se identificavam e a rejeição comum do termo "refugiado" manifestam a expectativa de cada uma delas sobre a sua permanência no exterior: se desejavam que fosse breve ou se não enxergavam mais possibilidade de retorno à terra natal. Dada a insuficiência de cada termo para designá-los, Burke opta pela neutralidade do termo "emigrante" ou "emigré", pois ele abarcaria todos os tipos de deslocados. Seu uso, entretanto, não é padronizado ao longo do livro e o assunto mereceria maior aprofundamento.

Esse novo olhar para os intelectuais forçados ou convidados ao deslocamento ilumina uma face quase impensável do exílio: seus ganhos. Ele aponta que, mesmo em decorrência de circunstâncias desfavoráveis, a troca de experiências e modos de pensar geraram (e geram) contribuições importantes para o desenvolvimento do pensamento no Ocidente, que também se valeu e muito do conhecimento de outras regiões do globo. Com a abrangência de cinco séculos de história e uma amplitude geográfica intercontinental, a tarefa hercúlea de Burke é sintetizar estudos de caso de acadêmicos dedicados especialmente às humanidades e oferecer ao leitor um panorama de intelectuais e suas produções mais notáveis, além de considerações sobre sua postura diante da alteridade. É pena que não tenha mencionado, entre os trabalhos sobre o exílio no Brasil, a tese de Izabela Kestler, publicada em alemão em 1992 e traduzida para o português por Karola Zimber: Exilio e literatura: escritores de fala alemã durante a época do nazismo (Edusp, 2003).

Burke conciliou a história do conhecimento com a história das diásporas, demonstrando como esta contribuiu para o desenvolvimento daquela. $\mathrm{O}$ deslocamento de pessoas, seja por motivos religiosos, políticos ou comerciais, faz com que os saberes trazidos por elas sejam deslocados, transplantados e, naturalmente, gerem novas descobertas como frutos.

No emigrante, o choque do exílio envolve quase sempre a perda da antiga língua, dos vínculos afetivos e da identidade individual. Num primeiro momento, poderia parecer que Burke escreve com este trabalho, pleno de empatia, a história dos perdedores ou dos vencidos, à lembrança das teses de Walter Benjamin em "Sobre o conceito da História". Pois, essa história é narrada de modo que nela seja valorizada a experiência de pessoas acossadas e sobreviventes que deixaram à posteridade uma marca singular de seu pensamento e de sua atuação social. Sua contribuição mais importante foi transmitir uma nova mentalidade, um habitus diferente daquele predominante no país de destino. Tais pessoas não só disseminaram conhecimento, como também combinaram novas abordagens e propiciaram inovações. As suas publicações foram importantes 
e ainda mais, foram, entre outros, a sua atividade de ensino e os encontros pessoais. No contato com alunos, docentes, assistentes, suas ideias impactaram e transformaram a tradição acadêmica das instituições que as receberam. Burke, no livro em pauta, prefere se concentrar nas consequências produtivas do exílio.

Para dar conta do extenso recorte temporal da pesquisa, o autor utiliza uma abordagem comparativa, apresentando estudos de caso detalhados da história do conhecimento na Europa e nas Américas. $O$ contraste central é estabelecido entre os exilados protestantes no século $x V I I$ e os exilados judeus do século $x x$. Por meio da prosopografia, o historiador configura uma biografia coletiva a partir dos imigrantes mais bem documentados ou "ilustres" e de suas carreiras. Porém, como um iceberg, há muito mais do que se vê. A investigação é pautada pelo "método regressivo", em que se dá enfoque às perguntas que os acadêmicos se fizeram, buscando respostas adequadas ao passado, ao tempo remoto e quer-se, sobretudo, "evitar respostas provocadas pelo presente, obliterando a alteridade e a estranheza do passado".

O termo guarda-chuva e o principal ganho do exílio na perspectiva do autor é a dupla desprovincialização, o alargamento dos horizontes tanto dos países que acolheram os emigrantes (exilados, expatriados etc.) quanto dos limiares destes mesmos indivíduos. Segundo Burke, provincialismo é "acreditar que sua comunidade está no centro do mundo". Esse processo de tomada de consciência, porém, é difícil e inclui situações dolorosas, resistência e mal-entendidos. Para o historiador, as novas ideias que os emigrados ganham são "um tipo de recompensa pela luta para sobreviver em uma cultura estrangeira". Assim, ao passarem de uma cultura a outra e apresentarem novos jeitos de pensar aos anfitriões, eles também desenvolviam uma outra maneira de pensar a própria cultura e adquiriam uma noção da "big picture" - expressão que permanece intraduzida no livro e, citando Alexis de Tocqueville, é ilustrada como a visão panorâmica de quem observa uma cidade do alto de uma colina.

São identificados três tipos de respostas dos emigrados às circunstâncias de vida no estrangeiro: mediação, distanciamento, hibridização. A primeira delas consiste na disseminação da cultura de origem no lugar de acolhimento, envolve a superação dos obstáculos linguísticos, evidencia o ensino de idioma, a elaboração de gramáticas, dicionários e a tradução como atividades mediadoras. $\mathrm{O}$ distanciamento pauta a concentração do exilado na sua cultura de origem, mesmo longe do seu país, o intelectual se sentirá um outsider dos dois lados, não procurará se adaptar ao ambiente onde se encontra e permanecerá desenraizado.

As obras escritas no exílio, como Casa-grande \& senzala (1933), de Gilberto Freyre, e Mimesis (1946), de Erich Auerbach, são exemplos da contribuição que o distanciamento proporcionou aos seus autores e, consequentemente, à compreensão dos respectivos países 
de origem. Contudo, quando Burke alude a Gilberto Freyre, citando Maria Lúcia Pallares-Burke, não deixa de ser curioso observar sua afirmação de que o brasileiro "construiu sua reputação desenvolvendo ideias que [Rüdiger] Bilden apresentara anos antes".

A terceira forma (e produto) da emigração, do exílio, da expatriação surge do desafio de pertencer às duas terras e observá-las criticamente. A hibridização supõe uma visão bifocal, nas palavras de Burke: cada qual ver-se como estrangeiro e fazer com que o ponto de vista de uma cultura complemente a outra. $\mathrm{O}$ intelectual "híbrido cultural" seria um novo tipo de personalidade. Burke propõe considerarmos o exilado o intelectual par excellence, um indivíduo "extraterritorial" (como disse Siegfried Kracauer), pois nem pertence à terra natal nem àquela que o acolheu. Só não é explicado por que o expatriado o seria "em menor medida" que o exilado.

Embora Burke, no começo, tenha optado pelo termo "emigrante" para designar toda a sorte de "deslocados" territoriais, a maior parte do livro refere-se à abrangência global do tema dos "exilados". Em se tratando da Era Moderna, o autor perpassa a queda da Constantinopla com a fuga dos gregos para a Itália, a fuga dos judeus da Espanha inquisidora para Amsterdã, considerada a "Jerusalém do Norte", para o norte da África e Império Otomano; muçulmanos, católicos e protestantes também são contemplados. Baruch Spinoza é um destaque nesse período. Para Burke, "sua vida entre culturas provavelmente o libertou de qualquer tipo de ortodoxia e o encorajou a desenvolver ideias originais". Quanto às perseguições religiosas, alega o historiador evidenciar-se a predominância do distanciamento como uma forma de preservação das tradições dos refugiados e suas famílias. Esse mesmo "distanciamento encorajou uma abordagem crítica do passado" e vale salientar que a produção intelectual no século xvı aponta "a consequente necessidade psicológica de explicar o desastre [da invasão da Itália pelos franceses em 1494]", de que surgiram "diversas histórias sobre o evento e seus desdobramentos". E isso ficará evidente também na literatura testemunhal e na investigação histórica das catástrofes do século $x x$.

Dedicando-se brevemente aos expatriados, Burke os organiza em três categorias: comerciais, religiosos e acadêmicos. Estes, muitas vezes, chegavam ao país anfitrião na condição de mediadores de um saber estrangeiro e, no trabalho conjunto com assistentes e estudantes locais, acabavam por se hibridizar, estimulando o desenvolvimento de novas ideias e práticas profissionais e científicas. Sendo, assim, o autor traduz inovação como "deslocamento de conceitos" e enfatiza que, por isso, não raras vezes ela venha de pessoas deslocadas.

$O$ trecho acerca dos acadêmicos franceses no Brasil é especialmente interessante. Sua presença foi crucial para o fomento do Ensino Superior no país devido à falta de instituições acadêmi- 
cas no período colonial, quando só era possivel obter um diploma na Europa. A fundação da Universidade de São Paulo, em 1934, contou, por exemplo, com a colaboração de intelectuais alemães e italianos nas ciências naturais e franceses sobretudo nas humanidades e ciências sociais. Estes compunham um grupo de jovens pesquisadores, dentre os quais apenas homens haviam sido oficialmente convidados, embora a participação da antropóloga Dina Lévi-Strauss como pesquisadora e docente ficasse subentendida no convite ao seu marido Claude Lévi-Strauss. Paul Arbousse-Bastide, ao relatar sua experiência na palestra $O$ que o Brasil me ensinou, mostra a Burke um olhar entusiasmado com a potência da diversidade no país, sintetizando sua impressão sobre a cidade de São Paulo como "um maraviIhoso ponto de encontro de culturas". No caso de Roger Bastide, que se especializou em religiões afro-brasileiras, a vinda ao país se fez determinante, observando à la Gilberto Freyre o sincretismo no candomblé como uma "interpenetração" de culturas. Muito da produção de conhecimento que se tem hoje no país se deve à presença e ao ensino desses e outros expatriados, mas, tanto aqui quanto em outros países, esse grupo em geral foi negligenciado pelos historiadores.

As perdas são evidentes quando consideramos as catástrofes do século xx. A vasta documentação da Segunda Guerra, por exemplo, torna reconhecível os efeitos negativos tanto na vida das pessoas forçadas a deixar sua terra natal como nos países reduzidos a escombros. Houve também uma perda intelectual enorme e irreparável desses países com a "fuga de cérebros"; em contrapartida, os países que acolheram esses deslocados foram beneficiados com a incorporação desses intelectuais entre os docentes de suas universidades. Aqui a hibridização foi privilegiada no comportamento dos estudiosos que puderam ocupar posições catedráticas nos países que os acolheram.

Referindo-se aos acadêmicos no campo da física, Burke exemplifica: "os emigrés foram descritos como 'construtores de pontes' que elaboraram 'sínteses' entre a tradição teórica alemã e a tradição anglo-americana de experimentos mais empíricos". O historiador percebe uma distinção por área de atuação quanto ao vínculo territorial anterior ao deslocamento: "Parece que as humanidades e mesmo as ciências sociais estavam mais enraizadas nas culturas nacionais do que as ciências da natureza". Em decorrência disso, o deslocamento gerou novas reflexões:

No longo prazo, pode-se dizer que os recém-chegados conseguiram fazer maiores contribuições a suas disciplinas nos países de acolhida exatamente por serem diferentes. Eles sabiam coisas diferentes, faziam perguntas diferentes, empregavam métodos diferentes e, em suma, ofereciam abordagens alternativas àquelas que dominavam o campo do saber em seu novo lar. (p. 200) 
Mas esse processo não foi fácil, houve muita desconfiança e críticas negativas devido à barreira da língua, à diferença na forma de estruturar o pensamento (uso de conceitos tendencialmente abstratos ou concretos), o método de trabalho (teórico ou empírico) e assim por diante. Professores perderam o status acadêmico e estudiosos tiveram que fazer um segundo doutorado no país de acolhida, pois este não reconhecia o primeiro. Além do problema da xenofobia, refugiados de fala alemã, por exemplo, sofreram com o equívoco de serem tomados por seus perseguidores nazistas. Em autobiografias e memórias, sobretudo dos exilados, está presente um conflito pessoal entre 0 desejo de assimilação cultural e o desejo de resistir a ela.

No epílogo da obra, Burke expõe também o exílio pós-1945 com os conflitos políticos na Polônia, Hungria, Tchecoslováquia e com os "golpes militares de 1964 no Brasil, de 1973 no Chile e 1976 na Argentina". Dos exilados brasileiros, o autor destaca o economista Celso Furtado, o educador Paulo Freire (notadamente mais reconhecido no exterior que no país de origem), o sociólogo e, décadas mais tarde, ex-presidente Fernando Henrique Cardoso e os historiadores José Honório Rodrigues e Emília Viotti da Costa.

As circunstâncias do século $x x$ trazem um aspecto novo e relevante: o número substancial de mulheres acadêmicas atuando nas universidades pela primeira vez na história. Burke oferece aos leitores, ao final do livro, uma lista de cem acadêmicas exiladas na década de 1930 das áreas de história da arte, história, línguas e literaturas, psicologia e sociologia. Este apêndice contém referências suficientes para estimular uma nova (e necessária) pesquisa inteiramente dedicada a essas intelectuais.

Evitando cometer alguma indelicadeza, o historiador não deixa de mencionar os problemas pessoais dos emigrantes e casos trágicos em que a dimensão traumática do exílio levou pessoas ao suicídio, como o escritor Stefan Zweig e o filósofo Edgar Zilsel, ambos austríacos. O alerta está presente, quando Burke diz que "é importante não pintar uma paisagem tão colorida", mas não por isso deve-se ignorar um lado bom decorrente da resiliência dos sobreviventes. Alguns decidiram recomeçar a vida sob um novo nome, a exemplo de Otto Maria Carpeaux, antes Otto Karpfen, e Rosa Stern, que se tornou Lucie Varga. Interpretar a adoção de uma nova identidade como uma forma de distanciamento poderia confirmar a ideia de Norbert Elias de que o distanciamento "é necessário à sobrevivência".

Quando Burke explica o distanciamento, ele identifica dois historiadores da Itália renascentista, Hans Baron e Nicolai Rubinstein; ambos, como sugere o autor, teriam escrito sobre a República Florentina pensando na República de Weimar, ou seja, na sua contemporaneidade. Isso para dizermos que Burke nos serve questões de um passado distante como o do século XVII e não tão distante como do XX, para, quem sabe, refletir 
também sobre a conjuntura política internacional da nossa atualidade e a necessidade diária de distanciamento e resiliência, de modo que os trabalhos de pesquisa continuem contribuindo com formas inovadoras de pensar.

MARIANA HOLMS é doutoranda em literatura alemã pela Faculdade de Filosofia, Letras e Ciências Humanas da USP, com pesquisa sobre a poeta exilada Paula Ludwig, e mestra em língua e literatura alemã pela mesma instituição, com estudo sobre a obra memorialística de Stefan Zweig. 